\title{
GÊNERO E EDUCAÇÃO, INTERFACES COM GRAFITOS EM UMA AMBIÊNCIA ESCOLAR:
} POSSIBILIDADES DE PESQUISA

\author{
Adriano Rogério Cardoso', Tânia Regina Zimmermann² \\ 'Mestrando do Programa de Pós-Graduação em Educação da Universidade Estadual de Mato Grosso do Sul - UEMS, \\ Unidade de Paranaíba, MS. Professor da Rede Estadual de Ensino de São Paulo. E-mail: adrianor345@hotmail.com \\ ${ }^{2}$ Doutora em História pela Universidade Federal de Santa Catarina- UFSC, Florianópolis, SC. Docente do curso de \\ História, Amambai, MS e do Programa de Pós-Graduação em Educação, Unidade de Paranaíba, MS da Universidade \\ Estadual de Mato Grosso do Sul - UEMS. E-mail: taniazimmermann@gmail.com
}

\section{RESUMO}

Este trabalho objetiva reflexões teórico-metodológicas em relação à pesquisa relativa as representações das sexualidades e de gênero em grafitos produzidos por adolescentes em uma Unidade Escolar no interior do Estado de São Paulo entre os anos de 2018 e 2019. Trata-se de um objeto de estudo de caráter políticopedagógico da educação, das relações sociais e não atrelado a questões meramente técnicas. Para a metodologia optamos pela pesquisa descritiva-exploratória, de cunho qualitativo. Utilizamos elementos da Análise Crítica do Discurso (ACD), pois contribuem para pensarmos o conjunto da produção dos grafitos vistos como textos, examinarmos aspectos linguísticos, imagéticos, sociocultural, reflexões sobre o processo da pedagogia presente nos grafitos, analisarmos as tramas discursivas do poder em nossa sociedade patriarcal e cristã. Nos grafitos coletados em ambiente escolar buscamos identificar e analisar anseios, dúvidas, construção de masculinidades e feminilidades, subjetividades bem como estigmas e preconceitos de gênero. Os resultados apontam a necessidade de reflexão, discussão, visibilidade dessa temática nos processos de formação profissional e continuada de professores, inclusão curricular, pois devido aos interesses político-pedagógicas na educação invisibilizou de seus documentos oficiais como na Base Nacional Comum Curricular questões de gênero e de sexualidade.

Palavras-chave: Educação. Gêneros. Sexualidade. Grafitos.

\section{GENDER AND EDUCATION, INTERFACES WITH GRAFFITI IN A SCHOOL ENVIRONMENT: RESEARCH POSSIBILITIES}

\section{ABSTRACT}

This work aims at theoretical-methodological reflections regarding the research concerning representations of sexualities and gender in graffiti produced by adolescents in a School Unit in the interior of the State of São Paulo between the years 2018 and 2019. It is an object of study of the political-pedagogical nature of education, of social relations and not linked to purely technical issues. For the methodology we opted for the descriptive-exploratory research, of qualitative nature. We use elements of the Critical Discourse Analysis (CDA), because they contribute to think about the production of graffiti as texts, examine linguistic, imagery, sociocultural aspects, reflections on the pedagogy process present in graffiti, analyze the discursive plots of power in our patriarchal and Christian society. In graffiti collected in a school environment, we seek to identify and analyze yearnings, doubts, construction of masculinities and femininities, subjectivities as well as gender stigmas and prejudices. The results point out the need for reflection, discussion, visibility of this theme in the processes of professional and continuing teacher training, curricular inclusion, because due to the political and pedagogical interests in education, it invisibilized from its official documents as in the National Curricular Common Base questions of gender and of sexuality.

Keywords: Education. Genders. Sexuality. Graffiti.

\section{GÉNERO Y EDUCACIÓN, INTERFACES CON GRAFITOS EN UN ENTORNO ESCOLAR: POSIBILIDADES DE INVESTIGACIÓN}




\section{RESUMEN}

Este trabajo apunta a reflexiones teórico-metodológicas sobre la investigación sobre representaciones de sexualidades y género en grafitos producidos por adolescentes en una Unidad Escolar del interior del Estado de São Paulo entre los años 2018 y 2019. Es un objeto de estudio de la naturaleza político-pedagógica de la educación, de las relaciones sociales y no vinculado a cuestiones puramente técnicas. Por la metodología optamos por la investigación descriptiva-exploratoria, de carácter cualitativo. Utilizamos elementos del Análisis crítico del discurso (ACD), ya que contribuyen a pensar en la producción de grafitos como textos, examinan aspectos lingüísticos, de imágenes, socioculturales, reflexiones sobre el proceso de pedagogía en el grafitos, analizan los argumentos discursivos del poder en Nuestra sociedad patriarcal y cristiana. En los grafitos recopilados en un entorno escolar, buscamos identificar y analizar anhelos, dudas, construcción de masculinidades y feminidades, subjetividades, así como estigmas y prejuicios de género. Los resultados señalan la necesidad de reflexión, discusión, visibilidad de este tema en los procesos de capacitación profesional y continua del profesorado, inclusión curricular, ya que debido a los intereses políticos y pedagógicos en la educación, se invisibilizó de sus documentos oficiales como en las preguntas de la Base Común Nacional Curricular sobre género y de la sexualidad.

Palabras clave: Educación. Géneros. Sexualidad. Grafitos.

\section{A. INTRODUÇÃO}

Os Parâmetros Curriculares Nacionais (PCNs), oriundos de 1997, propondo um trabalho transversal objetivam formação crítica para a cidadania. A diversidade sociocultural do país deve ser reconhecida. Os(as) alunos(as) devem aprender a se posicionar contra todos os tipos de preconceitos e discriminações. Os PCNs apontam a escola como um lugar adequado para trabalhar sexualidade (Orientação Sexual), principalmente devido ao tempo de permanência dos jovens na escola, as oportunidades de trocas de convívio social e relacionamentos amorosos ali vivenciados, prevenção da gravidez na adolescência, contaminação pelo vírus da imunodeficiência humana (HIV), que pode evoluir para Síndrome da Imunodeficiência Adquirida (AIDS) (BRASIL, 2001), favorecem a reflexão e discussões.

No entanto, isso parece ter tomado outro caminho, um retrocesso. Temas que deveriam ser trabalhados transversalmente no cotidiano escolar são vistos como temas tabus. Questões referentes a gênero e sexualidade foram invisibilizadas ou extintas dos documentos oficiais, como na Base Nacional Curricular Comum (BNCC) (BRASIL, 2018).

O Brasil é representado como nação paradisíaca que tolera e valoriza suas diversidades. A instituição carnavalesca possibilita que nossos desejos e identidades sejam aceitos, homens se fantasiam de mulheres e mulheres de homens, nesse período de festas. Temos a maior
Parada do Orgulho LGBTQIA+ (lésbicas, gays, bissexuais, travestis, transexuais, transgêneros, queer, intersexo, assexual) do mundo, na cidade de São Paulo. Entretanto, há no país uma política moral e religiosa instalada que coloca as margens comunidades minoritárias não hegemônicas. Segundo o Grupo Gay da Bahia (GGB) foram assassinadas 420 pessoas LGBTQIA+ por "crime de ódio" no ano de 2018. O país lidera o ranking internacional nessa modalidade (QUINALHA, 2019, p.4).

Em relação às mulheres no Brasil, em 2017, foram registrados 61.032 estupros, aumento de 10,1\% em relação a 2016. Em 2017, 1.113 foram vítimas de feminicídio e houve 221.238 registros de violência doméstica contra mulheres, corresponde a 606 casos por dia no país (FBSP, 2018, p.6).

Nas últimas décadas do século passado e início do século XXI, a educação brasileira tem sido fortemente influenciada pelas discussões sobre gênero e educação, movimentos LGBTQIA+, feministas e étnico-raciais têm procurado articular tais temáticas a fim de defender a formulação de políticas educacionais, compreensão da diversidade dos sujeitos que compõem o espaço educativo e, consequentemente, a prática pedagógica na educação escolar. Pensamos ser de grande importância sociocultural, as temáticas gênero e sexualidade em educação por estarem permeadas por uma série de preconceitos explícitos e velados em nossa cultura, além de 
possibilitar reflexão para cidadãos conscientes de seus direitos e subjetividades.

\section{B. DELINEAMENTO METODOLÓGICO}

$\mathrm{O}$ nosso interesse pela temática gênero e sexualidade na Educação desenvolveu-se em detrimento de observações locais sobre o elevado número de grafitos produzidos pelos alunos em uma ambiência escolar. Despertando-nos curiosidade sobre como a política educacional e social tem olhado para essas questões: gêneros e sexualidade em educação no contexto atual.

De acordo com Severino (2000, p. 145) a temática do trabalho acadêmico pode ou deve ser uma problemática reflexiva de procedência pessoal, autônoma, criativa, rigorosa, vivenciada pelo pesquisador e pode fazer parte dele, não apenas em nível sentimental. Mas o pesquisador deve avaliar a relevância e a significação dos problemas abordados inclusive para o próprio pesquisador, observando as relações do universo que os envolvem. Sendo assim, a escolha de um tema de pesquisa e sua realização é um ato político, isento de neutralidade, tendo uma dimensão social. Uma vez que o pesquisador já deve ter pensado a respeito de sua situação, mesmo no projeto e "nas tramas políticas da realidade social" que se encontram inseridos, envolvidos e concatenados (SEVERINO, 2000, p. 146).

Percebemos que a invisibilidade de tais temáticas reflete diretamente no currículo, nas políticas de formação de professores, na didática em sala de aula, no comportamento social dos alunos, apresentam consequências danosas que refletem na sociedade, evidenciadas em casos de violência e até morte contra mulheres e homossexuais. O que fazer? Como contribuir para evitar ou amenizar práticas de preconceito?

Imputar apenas a educação é algo inconcebível. Trata-se de um problema social que envolve outros setores como a família, leis, segurança, religião, estrutura social, saúde, educação. Compete a educação informar de modo qualitativo, reflexivo, crítico e não ocultar, empurrar para baixo do tapete, nem deixar para depois no sentido de formar cidadãos conscientes de suas subjetividades que tenham seus direitos, deveres respeitados e que respeitem as diferenças.

Em relação a postura do pesquisador Günther (2006) aponta que,

[...] além da influência de valores no processo de pesquisa, há de se constatar um envolvimento emocional do pesquisador com o seu tema de investigação. A aceitação de tal envolvimento caracterizaria a pesquisa qualitativa. Já a intenção de controlá-lo, ou sua negação, caracterizariam a pesquisa quantitativa. Da mesma maneira que os valores fazem parte da vida humana, o estudo das emoções é assunto importante da psicologia clínica e da personalidade, razão pela qual, mais uma vez, volta-se à questão mais relevante: como lidar com esta influência no contexto da pesquisa? (GÜNTHER, 2006, p. 203)

Pesquisar exige do pesquisador escolhas sobre o olhar. Exige responder questões sobre: o quê? Como? Em que direção? O pesquisador deve direcionar seu olhar e seus esforços investigativos. Para responder a essas questões faz-se necessária a tomada de decisões teóricas e metodológicas. Essas decisões irão servir de fundamentos, orientações ao trabalho de pesquisa e a construção dos caminhos para responder aos objetivos propostos.

No processo de pesquisa em Educação fazer as escolhas teóricas é algo desafiador. Pesquisar requer humildade para reconhecer que o conhecimento construído e as análises realizadas não podem ser totalmente controlados, tão pouco neutralizados. Nesse processo investigativo fazemos nossas escolhas, recortes e prioridades para evidenciarmos o objeto de pesquisa. No entanto calamos muitas vozes que outros poderão fazê-las ecoar em seus trabalhos investigativos.

A pesquisa que desenvolvemos é de abordagem qualitativa. Ghedin e Franco (2011) argumentam que abordagem não é propriamente o método. Para eles "é uma forma de, desde a borda, olhar aquilo que compõe o objeto em sua totalidade. Quando se fala em abordagem de pesquisa, está-se fazendo uma reflexão sobre como se deve conduzir o olhar na direção de determinados objetos" (GHEDIN; FRANCO, 2011, p. 28). Ao afirmarmos que nossa pesquisa é de abordagem qualitativa estamos nos referindo à 
maneira como olhamos ou lançamos nosso olhar para nosso objeto de pesquisa, como o abordamos teórica e metodologicamente em todas as etapas da investigação.

Para Bogdan e Biklen (1994, p. 11) a investigação qualitativa contempla "uma metodologia de investigação que enfatiza a descrição, a indução, a teoria fundamentada e o estudo das percepções pessoais". De acordo com Minayo e Sanches (1993, p. 245) "o trabalho qualitativo caminha sempre em duas direções: numa, elabora suas teorias, seus métodos, seus princípios e estabelece seus resultados; noutra, inventa, ratifica seu caminho, abandona certas vias e toma direções privilegiadas". Reverberam ainda que a metodologia qualitativa "trabalha com valores, crenças, representações, hábitos, atitudes e opiniões" (MINAYO; SANCHES, 1993, p. 247).

"A pesquisa qualitativa dirige-se à análise de casos concretos em suas peculiaridades locais e temporais, partindo das expressões e atividades das pessoas em seus contextos locais [...]" (FLICK, 2009, p. 37); possibilitando um deslocamento em diferentes caminhos; em sua estrutura possui rigor metodológico mantendo-se flexível e possibilita novas descobertas ou ampliação das existentes, proporcionando novos delineamentos que não seriam possíveis na pesquisa quantitativa (FLICK, 2009).

Ao longo do tempo foram surgindo "novas áreas e questões" entre elas "o sexo e o feminismo com a investigação qualitativa [...]" (BOGDAN; BIKLEN, 1994, p. 12). Na década de oitenta a teoria e a prática feministas influenciaram a investigação qualitativa, em relação ao tipo de sujeitos (feministas) estudados, assim como "os papéis psicossexuais", "análise de documentos", "história de vida e as entrevistas em profundidade", colocando em evidencia os "atores sociais, categorias de comportamentos previamente ignorados" (BOGDAN; BIKLEN, 1994, pp. 43-44). O foco de interesse de nossa pesquisa limita-se as questões de sexualidade e problemas de gênero expressos nos grafitos por adolescentes na ambiência escolar.

Acreditamos ser a abordagem qualitativa a mais apropriada para a realização dessa pesquisa descritiva-exploratória. Afinal como afirma Minayo (2010, p. 26) "[...] o objeto das ciências sociais é essencialmente qualitativo" e consideramos que melhor auxilia na compreensão desse fenômeno social exposto para esta pesquisa. A análise dos dados não ocorre apenas no final da pesquisa ela:

[...] se inicia já na fase
exploratória,
acompanhando toda a
investigação em uma
relação interativa com os
dados empíricos: à medida
que os dados vão sendo
coletado, o pesquisador vai
procurando
tentativamente identificar
temas er relações,
construindo interpretações
e gerando novas questões
e/ou aperfeiçoando as
anteriores, o que, por sua
vez, o leva a buscar novos
dados, complementares ou
mais específicos, que
testem suas
interpretações, r num
processo de "sintonia" fina
que vai até a análise final
(ALVES, 1991, p. 60).

Bogdan e Biklen (1994, p. 47) apontam cinco características da investigação qualitativa; 1 ) "a fonte direta dos dados é o ambiente natural" e o "investigador é o instrumento principal", é o pesquisador quem revisa o material coletado para sua compreensão e análise futura (BOGDAN; BIKLEN, 1994, p. 47); 2) "a investigação qualitativa é descritiva" (BOGDAN; BIKLEN, 1994, p. 48); 3) "os investigadores interessam-se mais pelo processo do que simplesmente pelos resultados ou produtos", isto é, levantam questões do tipo: "Como é que se começaram a utilizar certos termos e rótulos? Como é que determinadas noções começaram a fazer parte daquilo que consideramos ser o 'senso comum'?" (BOGDAN; BIKLEN, 1994, p. 49-50); 4) "os investigadores qualitativos tendem a analisar os seus dados de forma indutiva", não se presume que se sabe o suficiente antes de realizar a investigação, colhese o material, observa-se as partes para analisálas (BOGDAN; BIKLEN, 1994, p. 50); 5) "o significado é de importância vital na abordagem qualitativa" ou seja, como as pessoas dão sentido as suas vidas (BOGDAN; BIKLEN, 1994, p. 50).

Segundo Louro (2007) o olhar da linguagem no processo de pesquisa é considerada um meio descritivo e construtivo. O modo de apresentação da pesquisa pós-estruturalista se orienta no questionamento ao invés de apresentar meras conclusões ou respostas 
decisivas, possibilita a autoridade do pesquisador e incentiva a participação ativa do leitor. 0 questionamento demonstra atitude de se abrir para a diversidade. Não existe uma resposta única, mas sim possibilidades de ver várias coisas simultaneamente dependendo do ponto de vista de quem o analisa.

Nossa pesquisa procura investigar o movimento discursivo do poder, como ele acontece, como descobrir e descrever as relações de poder em uma sociedade patriarcal, heteronormativa e cristã? Muitas vezes tomadas como verdades cristalizadas e inquestionáveis. Autores como Foucault (1979), Fairclough (2001, 2016) e Teun van Dijik $(1999,2017)$ nos auxiliam nessa caminhada pela análise crítica discursiva.

\begin{abstract}
Uma das indagações mais frequentes no campo da pesquisa é a que se refere à representatividade da fala individual em relação a um coletivo maior. Tal indagação constituía uma preocupação de Bourdieu (1972) quando este definiu o conceito de habitus, segundo o qual a identidade de condições de existência tende a produzir sistemas de disposições semelhantes, através de uma harmonização objetiva de práticas e obras (MINAYO; SANCHES, 1993, p. 245-246).
\end{abstract}

Em outras palavras percebemos que há no contexto social brasileiro atual uma forte, cristalizada e íntima "associação com uma política moral e sexual", valores associados a defesa da família tradicional, heterossexualidade compulsória, religiosidade, regados com ataques verbais contra comunidades não hegemônica: "ter filho gay é falta de porrada" fala do ex-deputado, atual presidente do Brasil Jair Bolsonaro antes mesmo de ser eleito. Esse tipo de declaração restringe o direito da existência de um segmento da população (QUINALHA, 2019, p. 4).

0 interesse por essa temática surgiu devido as indagações pessoais e observações do elevado número de grafitos no ambiente escolar acompanhadas pelo quase silenciamento dos(as) professores(as) em relação a sexualidade na escola. Diante do exposto, definimos a seguinte questão norteadora: sexualidade e gênero: o que dizem os grafitos em uma ambiência escolar?

Tendo levantado a questão norteadora, o objetivo geral consiste em refletir de modo qualitativo as representações sexuais encontradas nos grafitos, produzidos por adolescentes em ambiente escolar, percebendo seus anseios, dúvidas, preconceitos sobre gênero e sexualidade; questionando sobre a problemática de sexualidade e gênero nos discursos das políticas curriculares na Educação.

Definimos os seguintes objetivos específicos:

1. Identificar as representações sexuais dos jovens a partir do conhecimento sobre sexualidade; observando seus anseios, dúvidas, preconceitos sobre gênero e sexualidade;

2. Classificar e analisar os grafitos de cunho sexual, encontrados no ambiente escolar;

3. Problematizar e refletir sobre as representações da sexualidade, relações de gênero, a existência do interdito no ambiente escolar e apontar possíveis direcionamentos;

4. Contribuir para desconstrução de preconceitos, estigmas, paradoxos sobre gênero e sexualidade entre adolescentes e a sua atuação no ambiente escolar e ao longo da vida.

Em relação aos Procedimentos e Instrumentos de Coleta de Dados esta pesquisa foi realizada em duas fases: 1- levantamento de pesquisa bibliográfica com o objetivo de encontrar trabalhos que permeiam nossa temática de interesse, sexualidade e gênero expressos pelos grafitos em ambientes escolares. 2- coleta de fotos: paralelamente foram sendo colhidas imagens no ambiente da escola pesquisada, para os procedimentos de classificação, análise e reflexão. Uma Escola Estadual "EE" localizada no município " $X$ ", Estado de São Paulo, foi palco para a coleta das imagens, por ser o local de trabalho do pesquisador "P1".

Para podermos discutir sobre a temática proposta inicialmente, realizamos uma pesquisa bibliográfica. Recorremos ao Catálogo de Teses e Dissertações da CAPES, a Biblioteca Digital Brasileira de Teses e Dissertações; Scielo; livros; anais de eventos e repositórios de teses e dissertações de algumas universidades, que abordem essa temática na área da educação. 0 recorte temporal para a realização do 
levantamento bibliográfico foi de 2008-2018, compreendendo, portanto, os últimos dez anos.

Para a captura das imagens foi utilizado um aparelho celular com câmera e sensor traseiro de 12 megapixels com abertura f/1.7 e tecnologia Dual Pixel, para melhorar o foco e deixar as imagens mais claras. Para Sontag (2004, p. 34) "[...] a imagem fotográfica possui uma ampla e naturalizada presença no imaginário social, o que Ihe confere um poder raro e ambíguo capaz de suscitar impotência e agressão, tédio e fascínio". Bogdan e Biklen (1994, p. 190-191) levantam questões interessantes sobre a utilização analítica das fotografias. Questões do tipo: "será que as fotografias tiradas por um investigador, ou qualquer outra pessoa, podem captar a vida interior de, por exemplo, uma escola? [...] Será que imortalizam aquilo que é apenas um momento num fluxo contínuo de acontecimentos?" "[...] As fotografias não são as respostas", porém devem ser vistas como "ferramentas para chegar às repostas" (BOGDAN; BIKLEN, 1994, p.191).

"O próprio ato de fotografar ou filmar um determinado evento já inclui a 'transcrição' de uma ideia em uma representação, no caso visual" (GÜNTHER, 2006, p. 205), porém não deve ser descartada a importância da observação do pesquisador que possibilita a reflexão dos dados colhidos, uma vez que o olhar do pesquisador poderá desvendar detalhes que poderiam estar oculto no recorte fotográfico, inclusive sobre o ambiente (BOGDAN; BIKLEN, 1994).

Percebemos que $o$ interesse e a exploração do uso na imagem passou a ter destaque social importante, isso nos mais diferentes campos: econômicos, sociais, políticos, sexuais e privados. A imagem é uma espécie de decalque do real que pode ser utilizado por instrumento de análise. Entende-se então que é "[...] um vestígio, algo diretamente decalcado do real, como uma pegada [...]" (SONTAG, 2004, p. 86).

O pesquisador com uma máquina fotográfica pode "coibir as pessoas" presentes em um ambiente (BOGDAN, BIKLEN, 1994, p. 140). No entanto, as fotografias para essa pesquisa foram tiradas em horários que não haviam alunos no ambiente, portanto trata-se de uma "ideia de produções típicas e naturais" dentro do contexto escolar, o pesquisador por não ser visto, não inibe ou interfere no ambiente nem nas produções dos grafitos; também não é tido como um intruso ou espião diante dos alunos ou das alunas.
Nessa pesquisa estamos interessados nas produções dos grafitos deixados diariamente no ambiente escolar, incluindo as carteiras, cadeiras, paredes, muros, pátios, portões, banheiros entre outros espaços. Em relação a análise de conteúdo a Bardin (1977) propõe: 1) a pré-análise; 2) a exploração do material; 3) o tratamento dos resultados, a inferência e a interpretação. Segundo Minayo (2010), o ciclo de pesquisa, compõe-se de três momentos: fase exploratória da pesquisa, trabalho de campo e tratamento do material.

Por meio da análise de conteúdo, a préanálise (BARDIN, 1977), de nossa investigação principiou-se na escolha dos documentos a serem analisados, ou seja, o corpus de análise, sendo eles:

1. Os artigos, dissertações, livros, que abordam os temas propostos nessa pesquisa sobre sexualidade, gênero e grafitos;

2. Trabalho de campo com a finalidade de encontrar os grafitos diariamente nos ambientes escolares e fotografá-los;

3. Realizar a classificação dos mesmos em categorias do tipo (corpo masculino, corpo feminino, xingamentos, órgãos sexuais entre outros);

4. Quantificação das imagens dentro das categorias identificadas;

5. Tabulação dos dados colhidos;

6. Transcrição dos textos encontrados nas fotos;

7. Análise e discussão dos dados.

A partir de leituras sucessivas de cada conjunto de material encontrado procuramos estabelecer alguns indicadores que expressam o essencial dos questionamentos em torno dos quais se construir a presente pesquisa. Em relação à Análise do Discurso (AD) "o termo Discurso não se aplica unicamente à linguagem mas a qualquer padrão de significado, seja ele visual ou espacial, e portanto pode referir-se a textos visuais, tais como a televisão, o cinema, a banda desenhada, etc." (WILLIG, 1999 apud NOGUEIRA, 2001, p.22). Nesse viés entendemos que os grafitos são textos verbo-visuais.

"Ao analisarmos o discurso, estaremos inevitavelmente diante da questão de como ele se relaciona com a situação que o criou. $A$ análise vai procurar colocar em relação o campo da língua (suscetível de ser estudada pela Linguística) e o campo da sociedade (apreendida pela história e pela ideologia)" (GREGOLIN, 1995, p.17). 
"Segundo Althusser (s.d.), a ideologia é a representação imaginária que interpela os sujeitos a tomarem um determinado lugar na sociedade, mas que cria a 'ilusão' de liberdade do sujeito. A reprodução da ideologia é assegurada por 'aparelhos ideológicos' (religioso, político, escolar etc.)" (GREGOLIN, 1995, p.18).

Optamos pelo uso da Análise Crítica do Discurso (ACD), pois pretende "aumentar a consciência de como a linguagem contribui para a dominação de umas pessoas por outras, já que essa consciência é o primeiro passo para a emancipação" (FAIRCLOUGH, 1989, p. 1). Também contribui para pensar elementos linguísticos, imagéticos com aspectos socioculturais.

Las prácticas discursivas
puedem tener efectos
ideológicos de peso, es
decir, puedem ayudar a
producir y reproducir
relaciones de poder
desiguales entre (por
ejemplo) las classes
sociales, las mujeres y los
hombres, las mayorías e las
minorías culturales o
étnicas, por medio de la
manera como representan
los objetos y sitúan a las
personas. (FAIRGLOUGH;
WODAK, 2000, p. 368).

O uso da ACD nos estudos de grafitos corrobora para perceber as construções sociais sobre as sexualidades, ainda polêmicas na escola, principalmente pela multiplicidade de visões, crenças, tabus, interditos, valores daqueles que nelas estão inseridos (BRASIL, 2001; SCHINDHELM, 2011; FOUCAULT, 1982). As questões de gênero perfilam uma complexidade. Os materiais didáticos, os currículos, a linguagem, imagens, organização do tempo, dos espaços educativos obedecem a uma lógica generificada de difícil percepção e escondem uma suposta naturalidade inclusive nos corpos. Essa naturalização nem sempre é problematizada e associada aos altos índices de violência contra comunidade LGBTQIA+, mulheres e crianças pelo país.

O material para análise está organizado em unidades de registro, aglutinados em temas e categorias que pudessem traduzir aspectos essenciais no sentido de responder às questões e objetivos de pesquisa. A quantidade de aparição da temática dos grafitos foi tomada como regra de contagem. Ao elaborarmos as categorias de análise dos dados procuramos observar características encontradas para atender aos objetivos da pesquisa.

Em relação aos cuidados éticos houve a necessidade de se preservar o anonimato dos dados dos produtores dos grafitos nos casos em que ocorreu identificação expressa: números de telefones ou nomes e sobrenome. Com isso preservamos os direitos dos produtores dos grafitos mantendo o anonimato e confidencialidade dos dados.

Em relação aos princípios éticos e em conformidade com a Resolução CNS 510/2016 como procedimentos iniciais da pesquisa foi estabelecido contato com a direção da Unidade Escolar para a realização da pesquisa; solicitou-se então uma autorização para o desenvolvimento da pesquisa, bem como, acesso as salas de aulas e ao ambiente escolar para poder produzir as fotos dos grafitos e utilizá-las para fins de divulgações acadêmicas.

No primeiro contato com a direção escolar realizamos a exposição dos objetivos da pesquisa e da metodologia para a coleta de dados. A direção da Unidade Escolar assinou um Termo de Consentimento Livre e Esclarecido e uma autorização que nos possibilitou a realizar a coleta de dados, assim como a utilização e publicação dos dados colhidos no interior da escola.

Seguimos os seguintes procedimentos:

1. Envio ao diretor da unidade escolar o Termo de Consentimento Livre e Esclarecido (TCLE), buscando explicitar os objetivos e procedimentos da pesquisa;

2. Respeitar os direitos dos envolvidos, o anonimato e a confidencialidade dos dados.

3. Antes de iniciar o processo de coleta das fotos nos ambientes da escola, solicitamos da direção uma autorização por escrito para a permissão de adentrar a Instituição de Ensino, fotografar para posterior edições e utilização das imagens para fins de publicações acadêmicos. Nossa solicitação foi autorizada.

\section{RESULTADOS E DISCUSSÃO}

Despertou-nos interesse em investigar esse fenômeno devido a observação in loco da constante e massiva produção de grafitos nesta ambiência escolar. Observamos uma profusão de pênis, xingamentos, atos sexuais, palavrões contínuos, entre outros. Quais seriam os motivos? 
O que levaria os adolescentes a tais produções em sala de aula e em ambiência escolar? Que pulsão latente é essa?

Procuramos realizar levantamento bibliográfico sobre pesquisas e produções sobre a temática gênero e sexualidade expressos por grafitos em ambiência escolar. No Brasil destacamos os trabalhos de Vilela (2017) que pesquisou grafitos relacionados a sexualidade em carteiras escolares no interior do estado de São Paulo. Gerbara e Souza (2016) pesquisaram 100 grafitos de conotação sexual em uma sala de aula, Ensino Médio e Curso Superior, nas (carteiras, paredes e portas) de uma instituição privada de ensino no estado do Mato Grosso do Sul. Realizaram análise discursiva das imagens, concluindo que os grafitos presentes simbolizavam expressões subjetivas de suas sexualidades protegidos pelo anonimato. Martins (2010) pesquisou grafitos em três escolas de Londrina observou paredes e carteiras, entrevistou alunos e diretores de escolas. A preocupação dos diretores estava voltada a limpeza das carteiras e ao conteúdo dos grafitos, muitas vezes pornográficos, contrários a moral e aos bons costumes. Entretanto, há outros trabalhos sobre grafitos latrinais relacionados à sexualidade.

Em nossa pesquisa a idade da clientela envolvida inicia-se a partir dos 11 anos e atualmente temos alunos(as) com 30 anos de idade no Ensino Médio. Trata-se de um grupo heterogêneo, há alunos(as) que possuem experiência sexual e outros(as) não, incluindo alunos(as) com filhos(as) e família constituídas a maioria não. A coleta dos grafitos foi realizada na "EE", Ensino Fundamental II e Ensino Médio, situada na mesorregião de São José do Rio PretoSP.

As fotos tiradas por celular no ambiente escolar, foram elencadas em categorias, numeradas, analisadas, buscando compreender as minucias, ambiguidades, tensões, preconceitos existentes nas relações de gênero e sexualidade no cotidiano escolar por meio dos grafitos expressos.

Acreditamos que os grafitos são um importante meio de comunicação dos adolescentes, que circulam pela instituição, um meio de expressão de suas vivências, seus anseios, dúvidas, repressões, representações sociais, podendo dar vasões por meio deles (FAIRCLOUGH, 2016).
Entendemos que o ato de grafitar é natural ao ser humano, deixar marcas por onde passa e vive inclusive modifica, altera, ou destrói o ambiente. Alguns indivíduos em sociedade constituem famílias, fazem filhos(as), deixam casas, bens materiais, escrevem e publicam livros e artigos, outros desenham, deixam grafitos em rochas, cavernas, banheiros públicos, ônibus, muros, edifícios, monumentos, troncos de árvores e por que não na escola? Talvez essa ação esteja relacionada à inconsciência ou consciência da finitude de cada um de nós, afinal, nascemos e caminhamos em direção ao fim, a morte.

Na pesquisa percebemos que as carteiras, cadeiras, portas, paredes e muros são espaços em que o privado se torna público. A maioria dos grafitos nesta pesquisa foi produzida com uso de lápis ou caneta; constantemente são alterados, refeitos, sofrem intervenções e/ou complementações por outros(as) alunos(as), além do apagamento pelos funcionários responsáveis pela limpeza dos ambientes.

Questões de gênero e de sexualidade fazem parte do ser humano e não há meios de serem deixadas fora do ambiente escolar. Os grafitos de ordem sexual e de gênero, presentes em ambiência escolar, são representações importantes e também meio de comunicação dos jovens. As temáticas, gênero e sexualidade nem sempre podem ser verbalizadas, por serem consideradas temas tabus. Os adolescentes dão vasão aos anseios, angustias, dúvidas por meios dos grafitos (VILELLA, 2017).

A instituição escolar é detentora de poder. O poder discursivo é capaz de conduzir e produzir efeitos benéficos ou maléficos, imperativo, libertário ou castrativo; pode nos proporcionar liberdade ou nos aprisionar, dependendo dos interesses de quem detém os saberes (FOUCAULT, 1979). A escola possui papel discursivo duplo: repressora no sentido de manutenção da ordem "moral e dos bons costumes", no caso, heteronormativo dominante (VAN DIJK, 2017). Em casos extremos, alunos são reprimidos no sentido de limpar carteiras ou ambiente escolar por terem grafitado; por outro lado, a escola desempenha papel libertário: formar cidadãos críticos, conscientes de seus direitos, deveres relativos às questões de gênero e de sexualidade. Conforme reza a Lei de Diretrizes e Bases da Educação Nacional (LDB, Lei no 9.394/1996):
Artigo 1ㅇ - A educação abrange os processos 
formativos que se desenvolvem na vida familiar, na convivência humana, no trabalho, nas instituições de ensino e pesquisa, nos movimentos sociais e organizações da sociedade civil e nas manifestações culturais (BRASIL, 1996).

A LDB (1996) orienta pelos princípios éticos, políticos e estéticos que visam à formação humana integral e à construção de uma sociedade justa, democrática e inclusiva. Dentre as 10 Competências Gerias da Educação Básica na BNCC (2018) destacamos a oitava: "Conhecer-se, apreciar-se e cuidar de sua saúde física e emocional, compreendendo-se na diversidade humana e reconhecendo suas emoções e as dos outros, com autocrítica e capacidade para lidar com elas" (BRASIL, 2018, p. 10).

As questões relativas à diversidade humana, assim como o reconhecimento de suas emoções e as dos outros, incluindo aqui gênero e sexualidade são quesitos deixados às margens e tais termos são invisibilizados pela BNCC (2018). Muitos professores por questões políticas, religiosas, sociais preferem deixar esses temas as margens, assim como a BNCC (2018) o fez. Essas temáticas deveriam fazer parte dos processos de formação de todos(as) professores(as) e de forma continuada nas políticas educacionais.

Em relação aos grafitos presentes em salas de aulas, desde os sextos anos são encontrados grafitos de conotação sexual, afetiva ou amorosa. As informações apresentam, ainda, conteúdos das disciplinas escolares, resoluções aritméticas, regras gramaticais, lembretes e expressões em inglês, flores, animais, corações, foguetes e meios de transporte.

Entretanto conforme os(as) alunos(as) avançam em relação a idade estimulados pelas influencias ambientais, sociais, familiares, midiática vai aumentando o despertar para amizades próximas, estabelecem vínculos por afinidade, afeição, sexualidade e afetividades, como sugere a Fig. 1.

Figura 1. Escritas- "Meu love"

Fonte: Acervo fotográfico do pesquisador

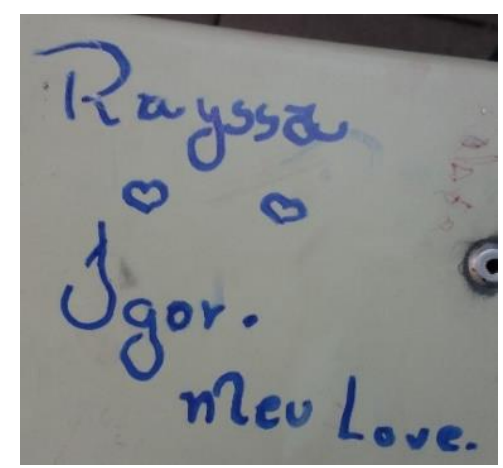

Os(as) alunos(as) dos sextos anos parecem não estarem tão propensos(as) ou despertos(as) em sua totalidade para questões de sexualidade. No entanto, é possível observarmos elementos da masculinidade e da feminilidade presentes nos grafitos em todos os anos e séries. São produzidos elementos que indiciam o universo ao qual desde cedo estão destinados homens ou mulheres.
Dizer que apenas os alunos grafitam seria uma inverdade. Ambos os gêneros confeccionam grafitos com temáticas distintas. As alunas geralmente são mais contidas e românticas conforme a Fig. 2, pois as normas $e$ as representações sociais mantêm o padrão normativo esperado do comportamento e postura do feminino hegemônico. 
Figura 2. Desenho-Representação Feminina

Fonte: Acervo fotográfico do pesquisador

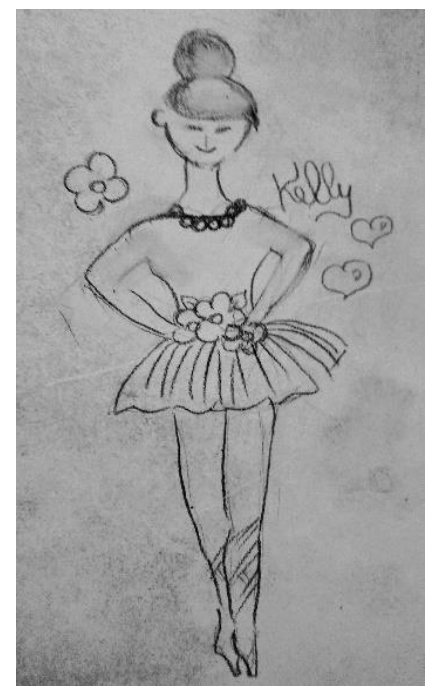

As meninas desenham bailarinas Fig. 2, escrevem seus nomes e os nomes das colegas, desenham flores, borboletas, corações, versos de músicas. Esses grafitos indicam representações sociais que $\mathrm{o}$ senso comum ensina como

Figura 3. Desenho-Representação Feminina pertencente ao universo masculino ou feminino. Isso se estende aos demais anos e séries do Ensino Médio.

Fonte: Acervo fotográfico do pesquisador

Em relação às mulheres prevalecem os elementos de valorização da feminilidade delicada, frágil, romântica na maioria dos grafitos observados. A partir dos sétimos crescem elementos de sexualidade Fig. 3 e se intensificam nos oitavos e nonos anos e nas séries posteriores. Cada vez mais surgem referências ao corpo nu, partes do corpo, surgem muitos grafitos com pênis, palavrões e xingamentos.

Vale ressaltarmos nas discussões relativas a feminilidade, no Brasil, em 2017, 4.539 mulheres foram vítimas de homicídio (aumento de $6,1 \%$ em relação a 2016 que foram 929 casos registrados) (FBSP, 2018, p.6). Talvez essa associação discursiva consagrada contribua com os índices de feminicídios. O feminino associado à fragilidade e o masculinidade a força, poder e virilidade.

Os grafitos produzidos pelos meninos apresentam dimensão despojada, audaciosa, continua. Os meninos desenham animais selvagens, ferozes, dinossauros, dragões, monstros, touros, cavalos, além de foguetes e tanques. Há muitas representações de figuras 
masculinas, lutando, atos sexuais, pênis Fig.4

(encontrado em um muro).

Figura 4. Desenho- Pênis

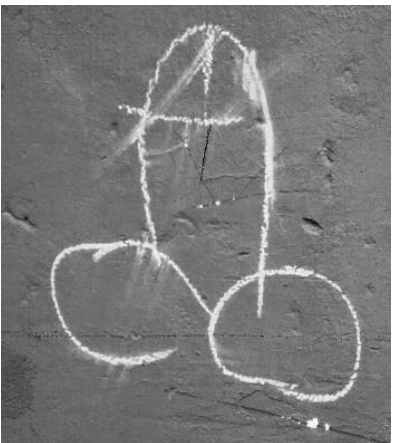

Fonte: Acervo fotográfico do pesquisador

Nesta pesquisa identificamos que a maioria dos grafitos são produções masculinas. As temáticas são destinadas a sexualidade, profusão de pênis eretos ejaculando em diversos tamanhos e formatos, atos sexuais predominantes relacionados a heteronormatividade, palavrões relacionados aos órgãos genitais masculinos e femininos, corpos masculinos musculosos, viris, carros esportivos, armas de fogo, facas, espadas, flechas, figuras masculinas fumando, grafitos representando folhas de cannabis sativa (maconha) em diversos locais, práticas esportivas, super-heróis masculinos: Superman e Batman Fig. 5.

Figura 5. Desenho- Batman

Fonte: Acervo fotográfico do pesquisador

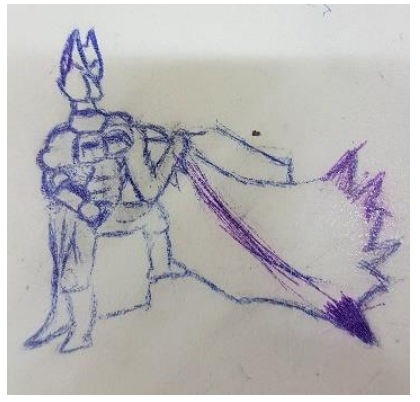

Na sociedade em que vivemos espera-se que o masculino apresente características de macho, ativo e viril, distanciando dos atributos de feminilidade. Tais grafitos nos permitem sugerir investigações futuras, em escolas, relacionadas a cultura pedagógica da masculinidade e também nos processos de formação de professores.

Percebemos que a partir dos sétimos anos até as terceiras séries do Ensino Médio há o aflorar para a sexualidade, principalmente por parte dos meninos. Acreditamos que o grande número de pênis grafitados sejam produções masculinas, assim como a grande maioria dos palavrões e xingamentos palavras: porra, cu, buceta, caralho, rola grande Fig. 6, foder e etc. 
Figura 6. Escrita- Referencia tamanho do Pênis

Fonte: Acervo fotográfico do pesquisador

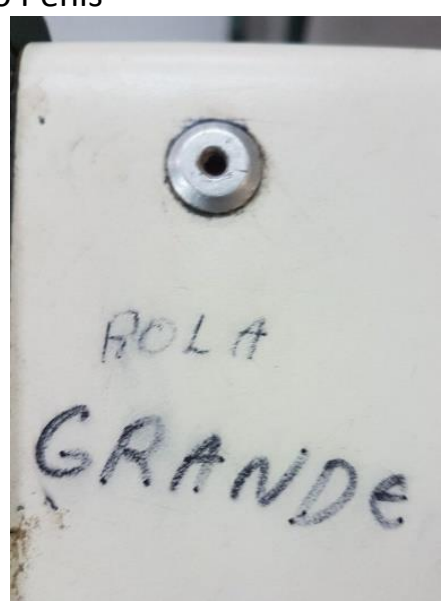

Os grafitos demonstram que as representações sociais observadas nesta escola referem a valorização do masculino e do seu universo. São representações sociais relacionadas ao que o senso comum dita como norma social.
Ao masculino fazer uso de cigarros, drogas, consumo de bebidas etílicas, devem ser ativos sexualmente, livres, xingam Fig. 7, apresentam traços de violência e agressividade.

Figura 7. Escrita- Xingamento "viado"

Fonte: Acervo fotográfico do pesquisador

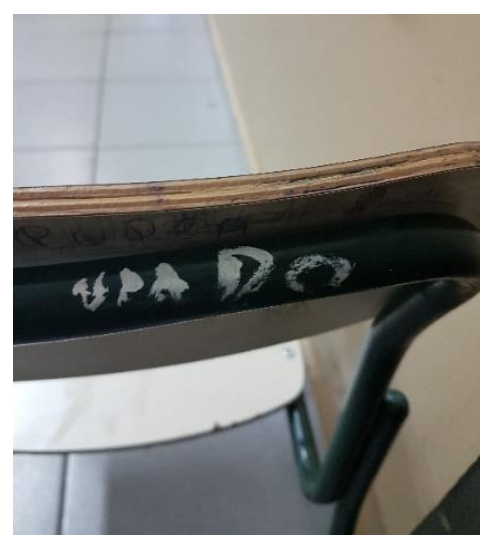

Muitos grafitos trazem nomes masculinos acrescidos com adjetivo "viado" como forma depreciativa, ofensiva, preconceituosa; na parte de traz de algumas cadeiras escolares há escritas dos termos "viado" (Fig.7); em outras cadeiras encontramos os dizeres "pega na minha bunda, $\mathrm{cu}$ grátis" seguidas por setas indicativas de onde se deve pegar. Há uma valorização do pênis que, na maioria das vezes, são desenhados eretos, com duas bolas grandes simbolizando os testículos sugestionando a importância em se ter culhões, ser macho e viril, atributos esperados em uma sociedade patriarcal, heteronormativa e cristã.

No universo masculino, elementos e práticas homoafetivas são pouco expressas nessa ambiência escolar como práticas naturais e aceitáveis. Na maioria das vezes apresentam caráter depreciativo aos movimentos LGBTQIA+ e feministas, ou seja, raras são as expressões não hegemônicas como a Fig. 8 que resistem e insistem em se erguerem nesse universo hegemônico heteronormativo. 
Figura 8. Desenho- Relação sexual homossexualidade

Fonte: Acervo fotográfico do pesquisador

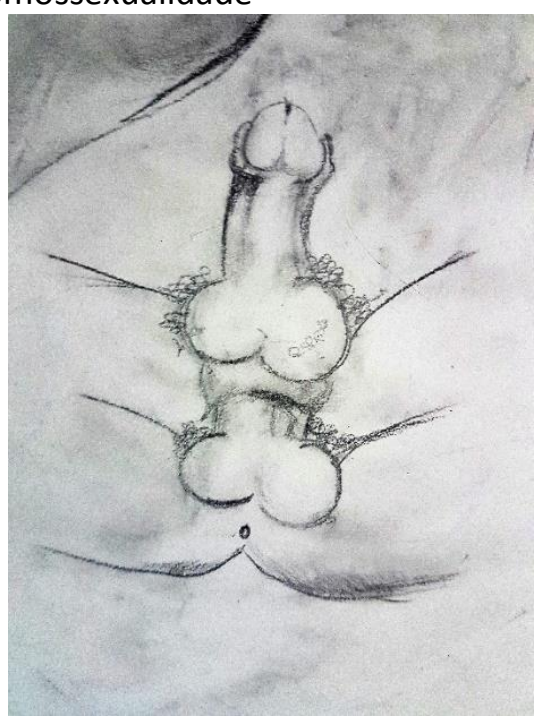

A ONG Mães pela Diversidade "acreditam que o que fomenta o preconceito é a falta de informação e a ignorância" e que lendas do tipo que LGBTQIA+ são opções, pois muitos(as) filhos(as) expressam sexualidade e identidade de gênero desde a primeira infância. Pais não são culpados pela "orientação sexual e identidade de gênero dos filhos", pois nem todos(as) os(as) filhos(as) de uma mesma família são gays e lésbicas. A erotização de crianças e a pedofilia devem ser combatidas uma vez que o desejo sexual surge na adolescência para todos(as). Os rótulos de promiscuidade, marginalidade, o bullying, práticas preconceituosas presentes na sociedade devem ser destruídos (GIORGI, 2019, p.6).

Entre as Competências Gerais da Educação Básica da (BNCC, 2018) destacamos:

“9. Exercitar a empatia, o diálogo, a resolução de conflitos e a cooperação, fazendo-se respeitar e promovendo o respeito ao outro e aos direitos humanos, com acolhimento e valorização da diversidade de indivíduos e de grupos sociais, seus saberes, identidades, culturas e potencialidades, sem preconceitos de qualquer natureza." (BRASIL, 2018, p.10).
São palavras que deveriam ser entendidas com maior comprometimento no processo educacional e nas políticas educacionais vigente do país, no entanto pelo noticiário e pelas práxis educacionais em nosso recorte, estão distantes da realidade igualitária que preze pelo respeito às diferenças e subjetividades de cada indivíduo LGBTQIA+ e feministas.

Os grafitos refletem a sociedade no contexto escolar, os estigmas de preconceitos relativos a gênero, sexualidade, posturas, preconceitos, comportamentos esperado ao masculino e ao feminino são fortemente representados nos grafitos encontrados.

\section{CONCLUSÕES}

Estamos longe de decifrar os enigmas que motivam os adolescentes dessa Unidade Escolar a essa profusão de grafitos, nesse continuo processo de grafitagem em ambiência escolar. Começamos a desenhar possíveis causas motivacionais, mas sabemos que estamos distantes da(s) resposta(s) definitiva(s).

A pesquisa exige reflexão sobre questões teórico-metodológicas: O quê? Como? Em que direção devemos direcionar nossos esforços investigativos? Questionando sobre a problemática de sexualidade e gênero nos discursos das políticas curriculares na Educação. Como é que começaram a utilizar certos rótulos e cristalizá-los? Como determinadas noções começaram a fazer parte do "senso comum"? Como movimenta o discursivo do poder? Como ele acontece? Como descobrir as relações de poder em uma sociedade patriarcal, 
heteronormativa e cristã? Outras questões deverão surgir como possibilidades investigativas.

Os grafitos de ordem sexual encontrados na ambiência escolar são vistos como em locais inadequados pelos professores e direção. Talvez, o que esteja inadequado seja o processo de formação dos professores que não foram contemplados com tal temática (gênero e sexualidade) em seu processo de formação e por conta disso não se sentem aptos(as) a abordar essa temática em sala de aula. Assim, como políticas curriculares educacionais que invisibilizam de seus documentos oficiais as questões de gênero e de sexualidade, contribuem para manutenção de tais temáticas as margens, por serem temas tabus.

Diante desse panorama, os alunos por não terem locais e momentos de fala sobre seus anseios, dúvidas, questionamentos sobre questões de gênero e sexualidade tendem a utilizar os grafitos como meio de expressões e representação social.

Advogamos a necessidade de problematizar questões de gênero e sexualidades nos discursos das políticas curriculares e nos processos de formação de educadores(as). Compete a escola a função de esclarecer, divulgar, ampliar a noção de conhecimento de todos a respeito do mundo que vivem, disseminando valores e hábitos de coexistência, urbanidade e acolhimento das diferenças, fazendo seu papel formativo institucional, mas imputar à escola a resolução dos problemas da sociedade. Há décadas discutimos que isso não é possível. A desconstrução de preconceitos e de estereótipos generificados possibilitam a formação de cidadãos críticos e conscientes em suas subjetividades.

\section{REFERÊNCIAS}

ALVES, A. J. O planejamento de pesquisas qualitativas em educação. Referências Cadernos de Pesquisa. São Paulo, n.77, p. 53-61, mai. 1991. Disponível em: http://publicacoes.fcc.org.br/ojs/index.php/cp/art icle/view/1042/1050 Acesso em: 16 jul. 2019.

BARDIN, J. L. Análise de Conteúdo. São Paulo: Martins Fontes, 1977.

BOGDAN, R. C.; BIKLEN, Sari K. Investigação Qualitativa em Educação. Uma introdução à teoria e aos métodos. Portugal: Porto Editora, 1994.
BRASIL. Ministério da Educação e do Desporto. Secretaria de Ensino. Base Nacional Curricular Comum. Brasília: MEC. 2018. Disponível em: http://basenacionalcomum.mec.gov.br/images/B NCC EI EF 110518 versaofinal site.pdf Acesso em: 7 jul. 2019.

BRASIL. Ministério da Educação e do Desporto. Secretaria de Ensino Fundamental. Parâmetros Curriculares Nacionais: Pluralidade Cultural: orientação sexual. Brasília: MEC, 2001.

BRASIL. Lei no 9.394, de 20 de dezembro de 1996. Estabelece as diretrizes e bases da educação nacional. Diário Oficial da União, Brasília, 23 de dezembro de 1996. Disponível em: http://www.planalto.gov.br/ccivil 03/leis/L9394.h tm. Acesso em: 07 jul. 2019.

BRASIL. Conselho Nacional de Saúde. Resolução no 510 de 7 de abril de 2016. Trata das especificidades éticas das pesquisas nas ciências humanas e sociais e de outras que utilizam metodologias próprias dessas áreas. Diário Oficial, 24 de maio de 2016. Brasília, 2016

FAIRCLOUGH, N. Discurso e Mudança Social. Brasília: Editora Universidade de Brasília, 2001.

FAIRCLOUGH, N.; WODAK, R. Análisis crítico del discurso. In: VAN DIJK, T. A. El discurso como interacción social. Estudios sobre el discurso II: una introcucción multidisciplinaria. Barcelona, Espanha: Gedisa, 2000, p. 367-404. Disponível em: https://libroschorcha.files.wordpress.com/2017/1 2/el-discurso-como-interaccic3b3n-social-teunvan-dijk.pdf Acesso em: 18 jul. 2019.

FAIRCLOUGH, N. Language and power. London: Longman, 1989.

FLICK, U. Introdução à pesquisa qualitativa. Porto Alegre: Artmed, 2009.

FÓRUM Brasileiro de Segurança Pública. 12 Anuário Brasileiro de Segurança Pública, v. 12., $\mathrm{n}$ 09 ago. 2018. 90 p. Disponível em: http://www.forumseguranca.org.br/wpcontent/uploads/2019/03/Anuario-Brasileiro-deSeguran\%C3\%A7a-P\%C3\%BAblica-2018.pdf Acesso em: 16 jul. 2019. 
FOUCAULT, M. História da Sexualidade I: A vontade de saber. 13.ed. Rio de Janeiro: Graal, 1982.

FOUCAULT, M. Microfísica do poder. Rio de Janeiro: Edições Graal, 1979.

GHEDIN, E.; FRANCO, M. A. S. Questões de método na construção da pesquisa em educação. São Paulo: Cortez, 2011.

GIORGI, M. Mães pela Diversidade "nossos filhos não vão ser estatística". In: LE MOND DIPLOMATIQUE BRASIL. v.12, n. 143, jun. 2019. p.6. Disponível em: https://diplomatique.org.br/edicao/edicao-143/. Acesso em: 16 jul. 2019.

GREGOLIN, M.R. V. A análise do discurso: conceitos e aplicações. Alfa, São Paulo, v. 39, p. 13-21, 1995.

GERBARA, J. A. S.; SOUZA, F. M. S. Análise do discurso de escritos em carteiras e paredes de sala de aula. Interletras, v.5, n.23, p. 1-11, 2016. Disponível em: http://www.interletras.com.br/ed anteriores/n23 Lconteudo/artigos/2.pdf Acesso em: 18 jul. 2019.

GUNTHER, H. Pesquisa qualitativa versus pesquisa quantitativa. Psic.: Teor. e Pesq., Brasília, v. 22, n. 2 , p. 201-210, 2006. Disponível em: http://www.scielo.br/pdf/\%0D/ptp/v22n2/a10v22

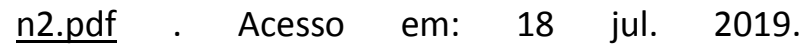
https://doi.org/10.1590/S0102$\underline{37722006000200010}$

LOURO, G. L. Gênero, sexualidade e educação: das afinidades políticas às tensões teóricometodológicas. Educação em revista. Belo Horizonte, n. 46, p. 201-218, 2007. Disponível em: http://www.scielo.br/pdf/edur/n46/a08n46

Acesso em: 18 jul. 2019. https://doi.org/10.1590/S0102-

$\underline{46982007000200008}$

MARTINS, J. B. Pichação na escola e a construção da identidade juvenil. In: ENCONTRO DE PESQUISA EM EDUCAÇÃO DA REGIÃO SUL ANPED Sul, 2010, 8., Londrina. Anais..., Londrina: UEL. 2010, p. 1-25. Disponível em: https://www.academia.edu/1960735/Picha\%C3\% A7\%C3\%A3o na escola e a constru\%C3\%A7\%C
3\%A3o da identidade juvenil Acesso em: 18 jul. 2019.

MINAYO, M.C.S.; SANCHES, O. Quantitativoqualitativo: oposição ou complementaridade? Cad. Saúde Públ., Rio de Janeiro, v.9, n.3, p. 239262, 1993. Disponível em: http://www.scielo.br/pdf/\%0D/csp/v9n3/02.pdf

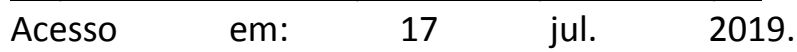
https://doi.org/10.1590/S0102-

$\underline{311 \times 1993000300002}$

MINAYO, M. C. S. (org.). Pesquisa social: teoria, método e criatividade. 29 ed. Petrópolis, Rio de Janeiro: Vozes, 2010.

NOGUEIRA, C. A análise do discurso. In: ALMEIDA, L.; FERNANDES, E. (Edts). Métodos e técnicas de avaliação: novos contributos para a prática e investigação. Braga: CEEP, 2001.

QUINALHA, R. Os direitos LGBT sob o governo Bolsonaro. In: Le Monde Diplomatique Brasil. Ano 12, n. 143, 2019. p.4-5.Disponível em: https://diplomatique.org.br/edicao/edicao-143/.

Acesso em: 16 jul. 2019.

SEVERINO, A. J. Metodologia do trabalho científico. 21.ed., São Paulo: Cortez, 2000.

SCHINDHELM, V. G. A sexualidade na Educação Infantil. Revista Aleph Infâncias. v.5, n. 16, 2011. Disponível em: http://www.revistaleph.uff.br/index.php/REVISTA LEPH/article/view/273/205 Acesso em: 18 jul. 2019.

SONTAG, Suzan. Sobre fotografia. São Paulo: Companhia das Letras. 2004.

TEIXEIRA BARTH, E. A Análise de Dados na Pesquisa Científica: importância e desafios em estudos organizacionais. Desenvolvimento em Questão, v. 1, n. 2, jul-dez., 2003, pp. 177-201. Disponível em: https://www.revistas.unijui.edu.br/index.php/des envolvimentoemquestao/article/view/84 Acesso em: 18 jul. 2019. https://doi.org/10.21527/2237$\underline{6453.2003 .2 .177-201}$

VAN DIJK, T. A. Analisis Critico del Discurso. In: Anthropos, Barcelona, 186, set./out., 1999, p.2336. Disponível em: http://www.discursos.org/oldarticles/El\%20an\%E 
1lisis\%20cr\%EDtico\%20del\%20discurso.pdf.

Acesso em: 24 abr. 2018.

VAN DIJK, T. A. Discurso e Poder.2. ed., São Paulo:

Contexto, 2017.

VILELA, G. J. D. Um Estudo sobre representações de sexualidade e atitudes sexuais de adolescentes de uma Escola Pública: análisedescritiva de grafitos em carteiras escolares. 2017. Dissertação (Mestrado em Educação Sexual) Universidade Estadual de São Paulo, Araraquara, 2017. 